\title{
Áreas Vulneráveis à Ocorrência de Acidentes Envolvendo Transporte Rodoviário de Produtos Perigosos no Trecho Alagoano da Rodovia BR-101
}

\section{Vulnerable Areas to the Occurrence of Accidents Involving Road Transport of Dangerous Products in the State of Alagoas' Section of Highway BR-101}

\author{
Esdras de Lima Andrade* $\bowtie$ (iD), Silvana Quintella Cavalcanti Calheiros $\bowtie$ (iD), \\ Melchior Carlos do Nascimento $\varangle$ (D), Sinval Autran Mendes Guimarães Junior $₫$ (iD \\ Instituto de Geografia, Desenvolvimento e Meio Ambiente, Universidade Federal \\ de Alagoas - Maceió, Alagoas, Brasil. \\ E-mails: qsilvana@uol.com.br (SQCC); melchior.nascimento@igdema.ufal.br (MCN); \\ sinval.autran@igdema.ufal.br (SAMGJ). \\ *E-mail para correspondência: esdras.andrade@igdema.ufal.br (ELA).
}

Recebido (Received): 10/07/2019

Aceito (Accepted): 7/10/2019.

\begin{abstract}
Resumo: O transporte de produtos químicos perigosos, enquanto parte integrante da cadeia produtiva, é considerado um fator de risco a acidentes, pois os sinistros podem ocorrer em qualquer lugar ao longo da rota. Nesse sentido, buscou-se identificar, localizar e mensurar as áreas vulneráveis sujeitas a sofrerem prejuízos materiais, humanos e ambientais na área de influência da Rodovia BR-101 que traspassa o território alagoano. $\mathrm{O}$ entendimento de áreas vulneráveis abordado neste trabalho agrega os fatores suscetibilidade e criticidade, já que são compostos por variáveis que apresentam características potenciais de serem impactados negativamente quando da exposição dos meios físico e antrópico aos produtos perigosos. Esses fatores foram integrados em um ambiente de sistema geográfico de informação, através do emprego de análise multicritério, mediante a estrutura integradora de média ponderada. Tal procedimento resultou em um mapa sinótico composto por quatro classes, ordenadas por níveis de vulnerabilidade, variando de muito baixa à alta. Destes, as classes somadas de baixa e média vulnerabilidade representaram $79,44 \%$ da área estudada. De modo geral, essas áreas abrangem terras usadas para fins de atividades agropastoris, como a criação extensiva de bovídeos e o cultivo da cana-de-açúcar. A classe de alta vulnerabilidade abrange uma proporção de $18,76 \%$ da mesma superfície analisada e os corpos d'água, os assentamentos humanos e as unidades de conservação da natureza se apresentam como locais demasiadamente críticos em situações de contato com as implicações dos produtos perigosos. Por fim, conclui-se que a variável criticidade tende a definir as áreas classificadas como de maior vulnerabilidade.
\end{abstract}

Palavras-chave: Vulnerabilidade; produtos químicos; geoprocessamento; modal rodoviário.

Abstract: The transport of dangerous chemicals, as an integral part of the production chain, is considered a risk factor for accidents, as accidents can occur anywhere along the route. In this sense, we sought to identify, locate and measure vulnerable areas subject to material, human and environmental damage in the area of influence of Highway BR-101 that crosses the territory of the state of Alagoas. The understanding of vulnerable areas addressed in this paper adds the factors susceptibility and criticality since they are composed of variables that have potential characteristics of being negatively impacted when exposing the physical and human resources to dangerous products. These factors were integrated into a geographic information system environment, through the use of multicriteria analysis, through the integrative structure of weighted average. Such procedure resulted in a synoptic map consisting of four classes, ranked by levels of vulnerability, ranging from very low to high. Of these, the combined classes of low and medium vulnerability represented $79,44 \%$ of the studied area. In general, these areas cover lands used for agropastoral activities, such as the extensive rearing of cattle and the cultivation of sugarcane. The high vulnerability class encompasses a proportion of $18,76 \%$ of the same surface area analyzed and water bodies, human settlements, and nature conservation units present themselves as too critical locations in situations of 
contact with the implications of dangerous products. Finally, we conclude that the criticality variable tends to define the areas classified as most vulnerable.

Keywords: Vulnerability; chemicals; geoprocessing; modal road.

\section{Introdução}

O Brasil conta atualmente com uma malha rodoviária de aproximadamente $1.720 .643,20 \mathrm{~km}$, segundo dados da Confederação Nacional do Transporte (2018), distribuída pelas cinco regiões administrativas do país, de maneira que integra todos os estados nas jurisprudências federal, estadual e municipal. Essa malha é responsável por cerca de $67 \%$ do volume de cargas transportado no território nacional, de acordo com o Instituto de Logística e Supply Chain (2016).

O modal rodoviário brasileiro começou a ganhar importância a partir de 1926 quando foram estabelecidas as bases da Rede Nacional Rodoviária, as quais se deram através do Plano Catrambi, no qual foram idealizadas as dezessete categorias de estradas troncais de penetração do território brasileiro (COIMBRA, 1974). Outras bases se sucederam no aperfeiçoamento de um Plano Rodoviário Nacional, com a intenção de interligar o país nos sentidos longitudinal e latitudinal, distendendo sobre todo o território brasileiro uma eficiente rede de comunicação e de escoamento da produção nacional (SERMAN, 2008).

Todavia, três acontecimentos foram primordiais na implementação deste modal em meados do século XX: a) a fundação da Petrobrás em 1953; b) a instituição da indústria automobilística nacional, focada na produção em grande escala, em 1957; e c) a construção da nova capital federal, em 1960, a qual permitiu a criação de uma malha viária que tornava Brasília o centro de um sistema que a interligaria a qualquer outro ponto do território brasileiro.

Inserida nessa vasta malha rodoviária, destaca-se a Rodovia BR-101, com uma extensão de $4.772,4 \mathrm{~km}$, o que corresponde a $0,28 \%$ de toda rede viária brasileira e, por isso, assume o status de rodovia mais extensa em solo nacional. De acordo com Coelho (2010), ela é considerada a espinha dorsal do Brasil, pois é tida como a principal via de transporte de cargas do país.

De acordo com o anuário estatístico das rodovias federais referente ao ano de 2010 (BRASIL, 2011), as estradas de jurisdição federal saltaram de 4.000 para 66.247 quilômetros entre 1952 e 2010 . No mesmo intervalo, a quantidade de acidentes aumentou de 1.748 para 182.900 . Em relação ao número de veículos de carga envolvidos em acidentes nessas rodovias, o aumento passou de 1.934 e alcançou 79.374 automóveis entre 1957 e 2010.

A realidade nas rodovias federais no Estado de Alagoas passou a ser registrada efetivamente a partir de 2007 até 2011 e contabilizou-se 7.275 acidentes envolvendo 17.133 veículos. Destes, 4.858, ou seja, 28\%, dizem respeito a caminhões, no qual somente 31 conduziam produtos químicos perigosos.

Todos esses números quando associados ao estado de conservação das rodovias, à precariedade da frota, ao estado físico dos condutores e às condições climáticas e de relevo podem favorecer consideravelmente a ocorrência de acidentes que envolvem esta tipologia de o transporte rodoviário; mostrando-se como um sério problema para o meio ambiente e para a saúde pública (IPEA; DENATRAN; ANTP, 2006).

Convém comentar que esta categoria de acidentes pode ocorrer em qualquer lugar ao longo da rota e as consequências são de difícil controle pelas próprias características comumente associadas, como a "descarga súbita de grande massa de produtos perigosos, fora e distante do parque industrial, locais próximos a comunidades, em geral carentes" (STRAUCH, 2004).

Tais eventos vêm ocorrendo em um número cada vez maior e têm afetado não somente os seus operadores - neste caso, os condutores e auxiliares -, mas também as populações lindeiras, o comércio, a indústria, o meio ambiente e muitas vezes alcançam outras regiões mais distantes levando à contaminação e à poluição, carreadas pelos ventos e sistemas hidrográficos, promovendo sérias consequências, muitas vezes catastróficas.

Nestes casos requerem-se medidas de alcance imediato, não só corretivas por ocasião dos sinistros, mas também preventivas, visando todas à redução possível de riscos e de seus efeitos impactantes.

Beltrami (2009) afirma que a exposição aos danos provenientes desses eventos ocorre quando as populações entram em contato com os produtos perigosos por uma ou mais vias, como a ingestão de água e 
alimentos contaminados, a inalação de poeiras tóxicas ou gases provenientes de vazamentos e incêndios, o contato dérmico com produtos corrosivos ou a complexa combinação desses fatores.

O mesmo autor cita ainda que as exposições podem ultrapassar os limites temporais, a depender das características e propriedades dos produtos envolvidos, como carcinogenicidade, mutagenicidade ou teratogenicidade.

Ao considerar que no Brasil a maior parte do transporte de cargas, inclusive de produtos perigosos, é realizado nas rodovias e que os acidentes representam a maior parte dos atendimentos de emergências realizados pelos atores ambientais, esta temática é extremamente relevante e merece atenção especial no contexto dos órgãos competentes para que seja garantida a qualidade ambiental no país.

A preocupação sobre esta temática começou a ser tratada no Brasil por meio da regulamentação do Decreto-Lei $\mathrm{n}^{\circ} .2 .063 / 1983$, após a ocorrência de tragédias como a explosão de um caminhão carregado de dinamites em 1972 no estado do Paraná; assim como a contaminação de vários operários num descarregamento de pentaclorofenato de sódio, conhecido como Pó da China, em 1977, no Mercado de São Sebastião, no Rio de Janeiro, vitimando fatalmente seis pessoas e causando doenças graves em outras tantas (COSTA, 2013).

Após esses feitos e na busca por se equiparar às legislações europeias e norte-americanas, sucederam-se outras legislações, resoluções e normatizações que tratam do transporte de produtos químicos perigosos no país.

Dentre esses documentos, ganha notoriedade aquele resultante da Convenção de Basiléia em 1989, organizada pela $\mathrm{ONU}$, que versou sobre o controle de movimentos transfronteiriços de resíduos perigosos e suas acomodações. Com esse intento, o governo brasileiro publicou o Decreto $\mathrm{n}^{\circ}$. 875/1993, o qual preconizava que o transporte de produtos perigosos fosse reduzido ao mínimo compatível com a administração ambientalmente saudável e eficaz desses produtos, a fim de proteger a saúde humana e o meio ambiente.

Antes disso, foi aprovada a regulamentação do transporte rodoviário de produtos perigosos pelo Decreto $\mathrm{n}^{\mathrm{o}} .96 .044 / 1988$.

Temas associados ao transporte rodoviário de produtos perigosos (TRPP) também foram tratados via legislação como a regulamentação do fundo especial para calamidades públicas (Decreto $\mathrm{n}^{\circ}$. 1.080/1994), dentre as quais incluem-se desastres com produtos perigosos.

Para todas essas legislações, os produtos perigosos são considerados, via de regra, todos aqueles que têm o poder de causar danos ou que representem risco à saúde humana, ao meio ambiente ou à segurança pública. Esses produtos estão relacionados ao transporte, de acordo com o Decreto ${ }^{\circ}$. 96.044, de 18/05/1988, que aprovou o Regulamento para o Transporte Rodoviário de Produtos Perigosos, constantes da Portaria $\mathrm{n}^{\text {}}$. 291, de 31/05/1988 (BRASIL, 1988), e da Resolução $n^{\circ}$. 420/2004 da ANTT, de acordo com os critérios dispostos no livro laranja (orange book) da ONU (UNITED NATIONS, 2017) nas quantidades consideradas perigosas.

O grau de risco associado aos sinistros envolvendo o TRPP não diz respeito somente ao tipo de produto químico transportado, mas sobretudo aos fatores de periculosidade inerentes ao percurso, tais como os fatores de fragilidade e de suscetibilidade dos elementos constituintes da paisagem, e aos fatores de vulnerabilidade ambiental e antrópicos. Quando combinados, estes fatores estabelecem um cenário potencial para causar múltiplos danos ao homem e ao meio, assim que expostos.

Nesse contexto, se faz necessário compreender os níveis de vulnerabilidade em que os recursos natural e humano estão sujeitos, baseados na suscetibilidade e criticidade potenciais das áreas afligidas pelos acidentes de natureza poluidora.

No entanto, é pertinente destacar que se entende por Áreas Críticas aquelas que são determinadas a partir de análises baseadas em distâncias. Isto é, considera-se a proximidade dos alvos de interesse em relação à distância das fontes de risco ambiental (CHAKRABORTY et al., 2011), sendo compostas por níveis de criticidade para os diferentes elementos naturais ou antrópicos, sujeitos a sofrerem diretamente o primeiro impacto causado por produtos perigosos, sejam eles através de escoamento de líquidos, pela dispersão eólica de gases, vapores e fumaças ou alastramento de fogo.

Quanto à suscetibilidade, concebe-se como a potencialidade de uma determinada área sofrer transformações no meio físico, decorrente de um evento potencialmente danoso, sem levar em consideração as consequências às atividades humanas, ou seja, é o meio por si só (ALONSO et al., 2004). A suscetibilidade representa ainda as características predisponentes do meio físico a qualquer dano, o que pode ser entendido como a fragilidade desse meio (ALHEIROS, 1996). 
Andrade (2016), ao propor a metodologia para a definição de áreas de risco, considera a vulnerabilidade como um dos elementos constituintes do conceito de risco ambiental, juntando-se aos componentes periculosidade e elementos expostos.

Nesta proposta, o conceito de vulnerabilidade se apossa da definição de Hossini (2008), que afirma que a vulnerabilidade é considerada em função da suscetibilidade e do grau de exposição ao perigo (criticidade). Este entendimento é complementado por Pécurto (2010), ao reiterar que a vulnerabilidade corresponde ao dano potencial decorrente de uma situação de risco.

Por sua vez, Cutter (1996) acrescenta o fator geográfico ao definir vulnerabilidade como "perigo do lugar", pois é nesse espaço que coexiste a condição preexistente da vulnerabilidade. O autor quer dizer que o lugar é suscetível aos danos e à capacidade de resposta aos eventos, isto é, à resiliência por parte dos meios natural e social aos graves eventos.

Nessa perspectiva, a vulnerabilidade, como parte do risco, assume o caráter geográfico do tema, ao associar o meio físico ao social. Brookfield (1999) corrobora com esse pensamento quando afirma que tanto as forças humanas quanto as forças naturais agem na produção da vulnerabilidade e, ao mesmo tempo, tornam-se vulneráveis uma à outra.

Assim como o risco está associado à presença humana, a vulnerabilidade só tem razão de sê-la se também houver a presença direta ou indireta do homem (REBELO, 2003); com isso, a vulnerabilidade torna-se o elemento de ligação entre o risco e o perigo.

Por fim, Santos (2015) afirma que em estudos ambientais, sempre devem ser considerados tanto os componentes naturais quanto os diferentes tipos de usos e ocupações do solo - que são a materialização das sociedades no espaço - para que se defina, assim, a fragilidade do ambiente em função das atividades humanas. Para que isso seja possível, é necessário, antes de tudo, conhecer suas causas e efeitos no espaço geográfico. E nos dias atuais deve-se se servir dos meios tecnológicos disponíveis no prognóstico do fenômeno em questão, a exemplo da cartografia e do geoprocessamento.

Neste sentido, a confecção de um mapa de áreas vulneráveis torna-se um poderoso recurso técnico que pode auxiliar na prevenção de acidentes, pois servem de base para elaboração de programas de redução de danos (ENOMOTO, 2004; FRIESECKE, 2004).

Isso posto, este trabalho tem por objetivo principal indicar e retratar as áreas vulneráveis a acidentes envolvendo TRPP na área de influência do trecho alagoano da Rodovia BR-101, a partir da utilização de parâmetros constituintes da paisagem, integrados em um ambiente de sistema geográfico de informação e fazendo uso de técnicas de geoprocessamento.

\section{Materiais e Método}

A metodologia adotada no trabalho envolveu, além do inventário e elaboração da base de dados físicoambiental proveniente de fontes primárias e secundárias; o levantamento bibliográfico, com vistas ao embasamento teórico-conceitual no tratamento e na elaboração dos respectivos dados e as atividades de campo que objetivaram calibrar os planos de informação empregados na avaliação e análise.

Para a identificação de áreas vulneráveis aos acidentes com produtos perigosos, foram adotados procedimentos e técnicas operacionais, baseadas em um Sistema Geográfico de Informações (SGI), no qual se utilizou os softwares livres QGIS 2.18, SAGA GIS 2.3 e GRASS 7.0.

\subsection{Caracterização da Area de Estudo}

Adotou-se como área de estudo uma faixa de 5 quilômetros no entorno do trecho alagoano da Rodovia BR-101, delimitação esta definida pela Comissão Estadual de Prevenção, Preparação e Resposta Rápida aos Acidentes e Desastres de Origem Tecnológica e Natural no Estado de Alagoas, em função da presença de importantes recursos naturais (mananciais e unidades de conservação) na área de influência direta da rodovia.

A área em questão limita-se ao Norte, na divisa dos municípios de Novo Lino/AL e Xexéu/PE, e ao Sul, na fronteira dos municípios de Porto Real do Colégio/AL e Propriá/SE (Figura 1). 


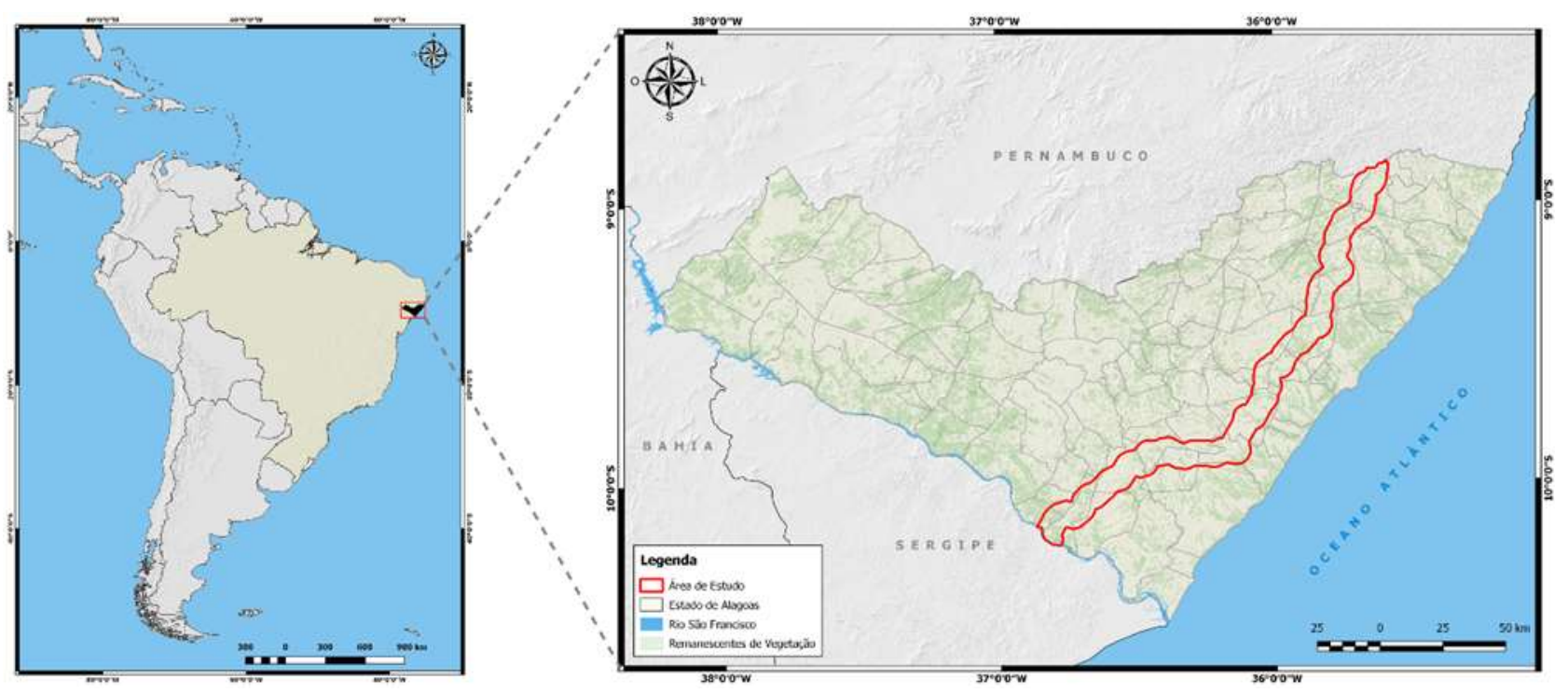

Figura 1. Localização da área de estudo. Fonte: Elaborado pelos autores.

Situa-se entre as coordenadas geográficas $8^{\circ} 50^{\prime} 26,42^{\prime \prime}$ e $10^{\circ} 15^{\prime} 23,97^{\prime \prime}$ de latitude Sul ao paralelo do Equador e $35^{\circ} 34^{\prime} 54,33^{\prime \prime}$ e $36^{\circ} 52^{\prime} 24,33^{\prime \prime}$ de longitude Oeste ao meridiano de Greenwich, estendendo-se por uma área de aproximadamente 2.370,66 $\mathrm{km}^{2}$ circunscrita em um perímetro de 483,36 quilômetros, em sentido longitudinal e abrangendo parte de 27 municípios situados na porção Leste do estado de Alagoas.

A climatologia preponderante corresponde aos tipos climáticos subúmido e subúmido seco e minoritariamente é influenciada pelo tipo úmido. Isso favorece temperaturas relativamente elevadas, com médias anuais em torno de $24^{\circ} \mathrm{C}$ a $26^{\circ} \mathrm{C}$, enquanto que as precipitações pluviométricas variam entre $800 \mathrm{e}$ $1.800 \mathrm{~mm} /$ ano, marcadas pelo predomínio de ocorrência das chuvas nas estações de outono e inverno.

Hidrograficamente, as 21 bacias hidrográficas abrangidas pela área de estudo apresentam um padrão de drenagem dendrítico e exorreico formado por canais que variam de $1^{\mathrm{a}}$ a $4^{\mathrm{a}}$ ordens, tendo em seus vales morfologias diferenciadas para cada trecho de curso. Os riachos são paralelos, com regime de enxurradas de outono, inverno ou por chuvas ocasionais de primavera.

A litologia é predominantemente dividida em três grandes unidades que, juntas, correspondem a $2 / 3$ da área estudada, sendo elas: a Formação Barreiras (ENb), o Complexo Nicolau-Campo Grande (APng) e a Suíte Intrusiva Itaporanga (NP3).

A morfologia do relevo apresenta poucas diferenciações, com um predomínio da unidade geomorfológica dos Tabuleiros Costeiros que se expressa numa faixa altimétrica de 50 a 100 metros, em média, tendo por característica marcante uma superfície tabuliforme de origem sedimentar, correspondente ao período Neógeno (antigo período Terciário); são cortados transversalmente por rios em cursos paralelos, conferindo variáveis graus de entalhamento, ora com vales estreitos e encostas íngremes, ora com encostas suaves e fundos com várzeas alargadas.

Destaca-se ainda a unidade das Encostas Orientais, que ocupa uma estreita faixa de terras na porção Centro-Norte do estado e é constituída pelo complexo cristalino do Planalto da Borborema, caracterizado por um extenso bloco estrutural de maciços falhados, modelados em rochas cristalinas.

Pedologicamente, dezesseis classes de solos compõem a área em questão. No entanto, três destas possuem relevância devido à sua representatividade, correspondendo aos Argissolos Amarelo (PA), Argissolos Vermelho-Amarelo (PvA) e aos Latossolos Amarelo (LA), os quais, somados, compreendem cerca de 80\% da área estudada.

\subsection{Dados Obtidos e Gerados}

O manual para implementação de planos de ação de emergência - para atendimento a sinistros envolvendo o transporte rodoviário de produtos perigosos, do Departamento Nacional de Infraestrutura e Transportes (2005) - estabelece alguns critérios para delimitação das variáveis dos meios físicos, bióticos e antrópicos na área de influência direta da rodovia, considerando os ecossistemas delimitados em função da extensão do alcance dos eventuais impactos decorrentes de possíveis acidentes com produtos perigosos, 
constituindo-se, assim, as variáveis definidoras para a análise. Entretanto, este documento permite a interpretação e a possibilidade de adoção de outras variáveis.

Assim, os dados geográficos foram organizados em dois grupos de variáveis, de forma que permitissem a geração de mapas sínteses referentes às áreas críticas e às áreas suscetíveis, tornando-os componentes da vulnerabilidade, conforme pode ser observado na Figura 2. Estes dados foram elaborados nas etapas anteriores da proposta metodológica de Andrade (2016), de sorte que a integração nesta fase se restringiu apenas nessas duas variáveis.

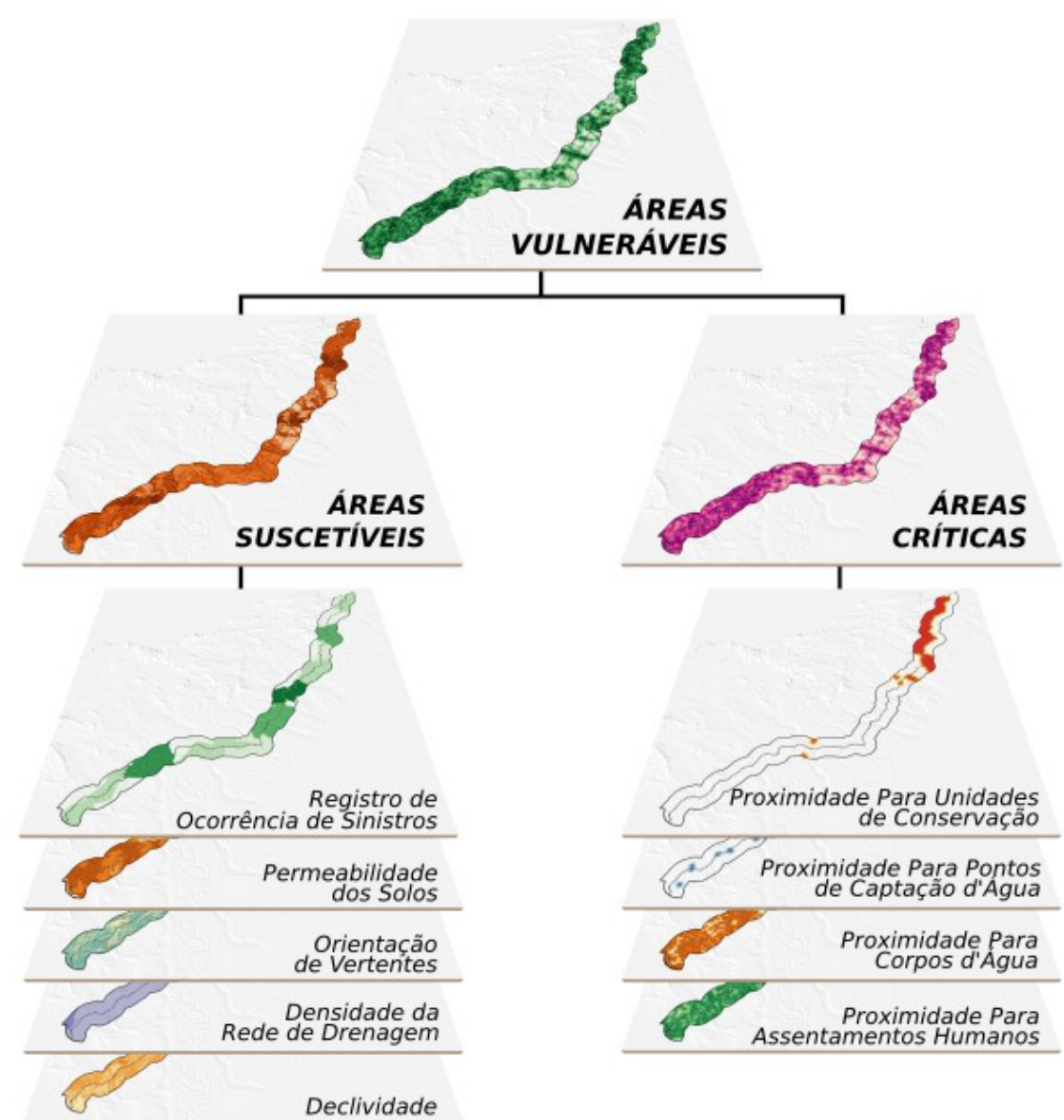

Figura 2. Base de dados geográficos utilizada na elaboração dos mapas sinóticos de áreas suscetíveis, áreas críticas e áreas vulneráveis a acidentes com transporte rodoviário de produtos perigosos. Fonte: Elaborado pelos autores.

\subsection{Integração dos Dados}

Devido à sua natureza integradora, o geoprocessamento dispõe de diversas técnicas de integração, sendo a álgebra de mapas a adotada neste trabalho. Esta consiste na aplicação de operações aritméticas voltadas à associação de vários planos de informação (variáveis), de modo a obter como resultado classificações que permitem análises diversas. Assim, o emprego da análise multicritério pelo algoritmo da média ponderada permitiu agrupar e classificar áreas que contribuem na identificação das áreas vulneráveis aos danos provenientes dos potenciais acidentes com transporte de cargas perigosas.

Em integrações realizadas por meio de média ponderada, cada mapa é ponderado pela utilização de pesos, distribuídos entre as variáveis até se atingir $100 \%$ da responsabilidade no fenômeno estudado, segundo o seu grau de importância. Quanto às classes pertencentes às variáveis adotadas, estas recebem notas de 0 a 10, conforme a possibilidade de sua associação com a ocorrência do fenômeno estudado.

Com base nisso, definiu-se que as classes com uma participação nula ou quase nula na ocorrência do fenômeno estudado recebessem notas 0 e 1 , respectivamente. As classes com uma pequena participação receberam notas de 2 a 4; já para aquelas com participação média, as notas variaram entre 5 e 6; e aquelas com grande participação, entre 7 e 8 . Nas classes em que as ocorrências eram muito possíveis e extremamente possíveis, foram atribuídas as notas 9 e 10, respectivamente. 
Os pesos e notas foram atribuídos com base no conhecimento teórico e prévio da área de estudo e também nas observações e anotações de campo, com vistas a equalizar os pesos e notas, a fim de se obter um produto verossímil junto à realidade.

De acordo com Calheiros (2000, p. 77), o algoritmo da média ponderada se dá pelo somatório do produto de pesos versus notas para cada célula (pixel) dos planos de informação submetidos à integração, de modo a resultar no mapa síntese para a finalidade desejada.

O algoritmo utilizado é representado pela seguinte expressão (Equação 1):

$$
A_{i j}=\sum_{k=1}^{n}\left(P_{k} \cdot N_{k}\right)
$$

Em que:

$A_{i j}=$ Célula qualquer da matriz

${ }^{n}=$ Número de parâmetros envolvidos

${ }_{k}=$ Plano de informação

$P=$ Peso atribuído do parâmetro, no intervalo de 0 a 1

$N=$ Nota atribuída à categoria encontrada na célula da matriz ( 0 a 10$)$

Para se chegar aos resultados de Áreas Críticas e Suscetíveis, foram realizadas integrações simples separadamente para cada tema, em que as variáveis foram combinadas de forma direta, ou seja, a partir dos conjuntos de dados originais (XAVIER DA SILVA, 2001, p. 175), decorrente da seguinte mecânica (Equação 2):

VariávelA + VariávelB $+(\ldots)+$ VariávelZ $=$ MapaSíntese $A$

Posteriormente, para se chegar ao mapa sinótico de áreas vulneráveis, recorreu-se ao processamento em que o modo de integração foi complexo. Xavier da Silva (2001) afirma que isto corresponde à combinação que usa integrações prévias como base para elaboração de um mapa final. Este processamento se exprime a partir da seguinte sintaxe (Equação 3):

MapaSintese A + MapaSinteseB = MapaFinal

Eq. 3

\subsection{Elaboração do Mapa de Áreas Vulneráveis}

Objetivando-se chegar ao mapa de Áreas Vulneráveis, foram conjugadas as variáveis de Áreas Críticas e Áreas Potencialmente Suscetíveis, às quais foram auferidos os pesos e notas, conforme Quadro 1.

Quadro 1. Atribuição de pesos e notas para as variáveis e respectivas classes utilizadas na integração.

\begin{tabular}{ccccc}
\hline Variáveis & Pesos & Classes & Notas & $\begin{array}{c}\text { Graus de } \\
\text { Possibilidade }\end{array}$ \\
\hline \multirow{3}{*}{ Áreas Suscetíveis } & \multirow{2}{*}{0,5} & Suscetibilidade Muito Baixa & 2 & Muito Baixo \\
& & Suscetibilidade Baixa & 3 & Baixo \\
& Suscetibilidade Média & 5 & Médio \\
& Suscetibilidade Alta & 7 & Alto \\
\hline \multirow{3}{*}{ Áreas Críticas } & \multirow{2}{*}{0,5} & Moderadamente Crítica & 2 & Muito Baixo \\
& & Crítica & 4 & Baixo \\
& & Muito Crítica & 6 & Médio \\
& & Demasiadamente Crítica & 8 & Alto \\
\hline
\end{tabular}

Fonte: Elaborado pelos autores (2019).

O procedimento de combinação de dados em ambientes de Sistemas de Informações Geográficas (SIG) se deu através da função Calculadora Raster do software QGIS, no qual foi possível executar a expressão matemática que permitiu a conjugação das variáveis conforme a Equação 4.

$$
A V=(A S \times 0,50)+(A C \times 0,50)
$$

Onde: 
$\mathrm{AV}=$ Áreas Vulneráveis

$\mathrm{SP}=$ Áreas Suscetíveis

$\mathrm{AC}=$ Área Críticas

Estas variáveis receberam peso de 0,5 , o que representa $50 \%$ de responsabilidade na elaboração do mapa de áreas vulneráveis, porque, conjugados, complementam-se na construção de um tema de magnitude mais abrangente, de modo a refletir os graus de vulnerabilidade ao risco a acidentes com TRPP.

As notas atribuídas consideraram as mesmas que retornaram como resultado, nas respectivas integrações anteriores que lhes deram origem, obedecendo, assim, ao grau de possibilidade de associação das classes com a ocorrência do fenômeno estudado.

\section{Resultados e Discussão}

A integração complexa, realizada mediante aplicação de média ponderada entre as variáveis anteriormente comentadas, retornou notas compreendidas entre 2 e 7, sendo, portanto, recategorizadas em quatro níveis de vulnerabilidade, nos quais o meio se sujeita ao grau de magnitude do dano potencial resultante de um cenário de risco.

Esses níveis de vulnerabilidade foram nominados seguindo a técnica da transposição de classes, pois se apresentavam na escala ordinal e foram portadas para a escala nominal; isso permitiu o agrupamento das categorias por níveis de similaridade.

Dessa forma, as notas 2 e 7 não sofreram aglutinamento, pois se apresentaram isoladas, mas foram reclassificadas como Muito Baixa Vulnerabilidade e Alta Vulnerabilidade, respectivamente. Já as notas 3 e 4 foram unidas em uma única classe e identificadas como Baixa Vulnerabilidade e as notas 5 e 6 foram agrupadas na categoria Média Vulnerabilidade (Quadro 2).

Quadro 2. Transposição das classes da escala ordinal para nominal do mapa de áreas vulneráveis.

\begin{tabular}{ccc}
\hline Notas & Classes Agrupadas & Ocorrência das Classes \\
\hline 1 e 2 & Muito Baixa Vulnerabilidade & Sim, apenas nota 2 \\
3 e 4 & Baixa Vulnerabilidade & Sim \\
5 e 6 & Média Vulnerabilidade & Sim \\
7 e 8 & Alta Vulnerabilidade & Sim, apenas nota 7 \\
9 e 10 & Muito Alta Vulnerabilidade & Sem ocorrência \\
\hline
\end{tabular}

Fonte: Elaborado pelos autores (2019).

As notas compreendidas entre 9 e 10 não foram expressas no resultado da integração, o que significa que não houve representações da vulnerabilidade muito alta.

Nessa perspectiva, após a planimetria realizada no cartograma de Áreas Vulneráveis, permitiu-se observar que a classe Média Vulnerabilidade (Notas 5-6) detém uma predominância espacial em relação às demais classes, pois estende-se por $134.723,23$ hectares, o que representa $56,83 \%$ da área total estudada (Tabela 1).

Tabela 1. Planimetria das áreas de vulnerabilidade.

\begin{tabular}{ccc}
\hline Classes & Área (ha) & Área (\%) \\
\hline Muito Baixa Vulnerabilidade (Nota 2) & $4.257,71$ & 1,80 \\
Baixa Vulnerabilidade (Notas 3-4) & $53.608,91$ & 22,61 \\
Média Vulnerabilidade (Notas 5-6) & $134.723,23$ & 56,83 \\
Alta Vulnerabilidade (Nota 7) & $44.476,85$ & 18,76 \\
\hline Totais & $\mathbf{2 3 7 . 0 6 6 , 7 0}$ & $\mathbf{1 0 0 , 0 0}$ \\
\hline
\end{tabular}

Fonte: Elaborado pelos autores (2019). 
Essa abrangência ocorre proeminentemente nas porções Norte e Sul, entre os municípios de Colônia Leopoldina e Novo Lino até Rio Largo, e de Teotônio Vilela a Porto Real do Colégio, respectivamente. Registram-se ainda pequenas ocorrências em Pilar, Boca da Mata, São Miguel dos Campos, Jequiá da Praia e Campo Alegre.

Estas áreas estão associadas a uma suscetibilidade considerada média, onde predominam solos com média permeabilidade, como os Argissolos, Gleissolos Háplicos, Latossolos Amarelos, Luvissolos Crômicos e os Planossolos Háplicos, acomodados sobre um relevo dominantemente que varia de plano a ondulado portanto, relacionados a uma rede de drenagem de densidade baixa. Nos municípios em que se expressam as feições de média vulnerabilidade, o registro de acidentes com TRPP indica até duas ocorrências.

Em relação à criticidade dessas feições, os assentamentos humanos e as unidades de conservação da natureza são consideradas áreas muito críticas aos efeitos dos produtos perigosos, provenientes de possíveis vazamentos das respectivas cargas.

A categoria Alta Vulnerabilidade compreende uma área de 44.476,85 hectares, equivalente a 18,76\% da superfície estudada. Sua distribuição espacial se dá de maneira esparsada, representada por pequenos fragmentos areais, entre os quais se destacam quatro dos de maior representatividade espacial: duas localizadas no Norte, uma em Novo Lino e Joaquim Gomes e outra em Flexeiras (Figura 3). No Centro, verifica-se uma área em Rio Largo e no Sul, uma no município de São Sebastião.

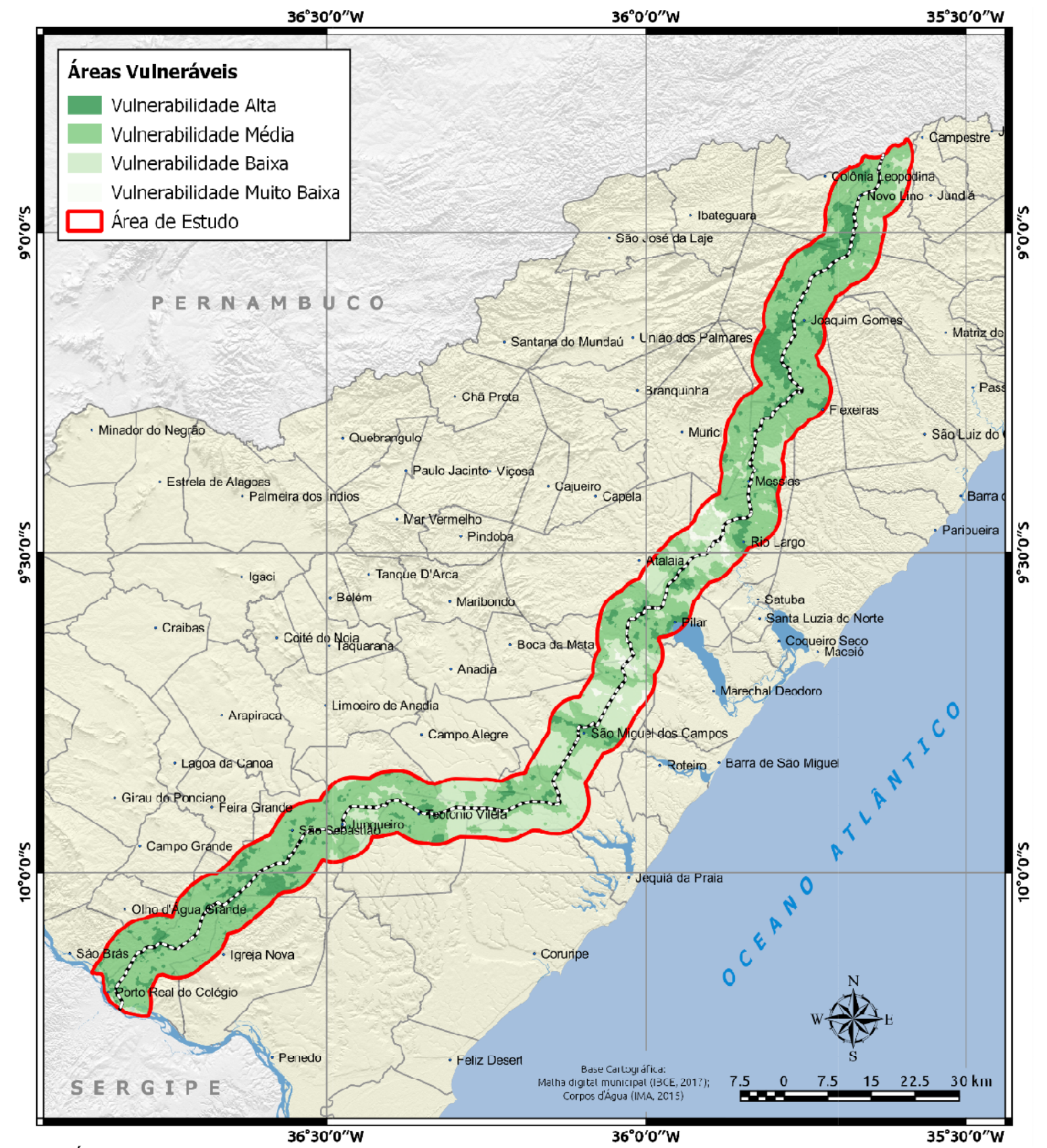

Figura 3. Áreas vulneráveis aos produtos químicos perigosos decorrentes de acidentes rodoviários, contidas na área de influência do trecho alagoano da Rodovia BR-101. Fonte: Elaborado pelos autores (2019). 
Essas áreas apresentam uma suscetibilidade considerada alta, onde predominam solos com baixa permeabilidade, dispostos sobre um relevo hegemonicamente que varia de ondulado a forte ondulado portanto, associados a uma rede de drenagem, ora de densidade medianamente baixa na porção Sul da área estudada, ora medianamente alta na porção Norte em questão. As vertentes voltam-se com mais frequência para orientações de norte $\left(0^{\circ}\right)$ a leste $\left(90^{\circ}\right)$. Nos municípios em que se expressam as feições de alta vulnerabilidade, os acidentes envolvendo TRPP registrados contabilizam áreas com quatro ocorrências.

Quanto à criticidade dessas feições, tanto os corpos d'água, quanto os assentamentos humanos e as unidades de conservação da natureza mostram-se como áreas demasiadamente críticas ao entrarem em contato com as implicações dos produtos perigosos.

A classe Baixa Vulnerabilidade se estende por uma área de 53.608,91 hectares, o que corresponde a $22,61 \%$ da área de estudo, distribuindo-se majoritariamente na sua porção Central, com destaque para dois trechos situados entre parte dos municípios que vai de Rio Largo até Pilar e de Boca da Mata/São Miguel dos Campos a Teotônio Vilela.

A suscetibilidade destas áreas é estimada como baixa porque ocupam espaços de plantio da Cana-deaçúcar nos platôs e interflúvios tabuliformes, em solos de permeabilidade muito baixa, devido à presença abundante dos Latossolos Amarelos que possuem uma textura que varia de argilosa a muito argilosa. No que diz respeito à densidade da rede de drenagem, sobressaem as medianamente baixas e medianamente altas, uma vez que o terreno é pouco movimentado, pois, a clinometria varia de uma topografia plana $(0$ a $3 \%)$ à suave ondulada (3 a 8\%). A distribuição espacial das orientações das vertentes mostra-se dividida equitativamente, com leve destaque para o sentido Sul $\left(180^{\circ}\right)$.

No que diz respeito à criticidade, os elementos constituintes desta variável se apresentam predominantemente distantes da rodovia, conferindo aos Pontos Outorgados de Captação de água, as Unidades de Conservação e os Corpos Hídricos a condição de moderadamente crítica às feições em questão.

Em relação à classe Muito Baixa Vulnerabilidade, devido à sua inexpressiva participação espacial e relevância na análise, prescinde-se de tecer maiores comentários.

Assim, de acordo com o que foi discutido anteriormente e através da análise da Figura 4 abaixo, constata-se que, em termos quantitativos, os graus de criticidade se relacionam espacialmente de forma direta com os níveis de mesma intensidade das classes de vulnerabilidade. Por exemplo, as áreas consideradas de alta vulnerabilidade estão diretamente ligadas às áreas extremamente críticas; nas áreas de vulnerabilidade muito baixa, sobressaem-se as áreas sem criticidade.

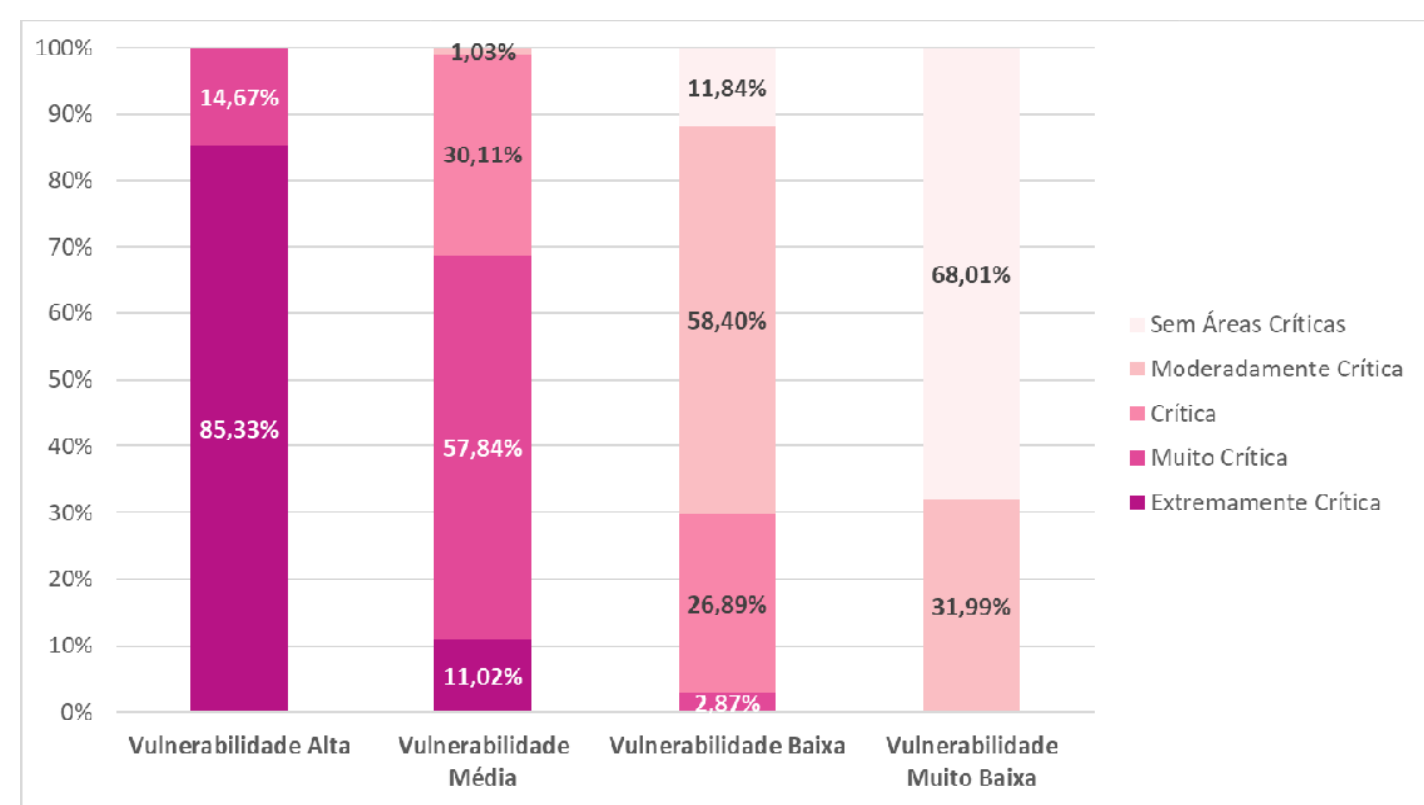

Figura 4. Distribuição percentual das áreas críticas no mapa de áreas vulneráveis. Fonte: Elaborado pelos autores.

Desse modo, a classe Vulnerabilidade Alta detém a participação majoritária no nível Extremamente Crítico, com 85,33\% da categoria em questão; isso corresponde a uma área de 37.951,73 hectares. 
$\mathrm{Na}$ classe Vulnerabilidade Média, a legenda Muito Crítica prevalece com uma parcela de 57,84\%, representando os 77.925,43 hectares de abrangência na classe.

A categoria Vulnerabilidade Baixa, por sua vez, apresenta um predomínio da criticidade moderada, computando $31.310,26$ hectares, o que equivale a 58,40\% desta categoria. Nisso, o grau crítico, que tem relação direta com o nível de vulnerabilidade, ocupa apenas $26,89 \%$ da área pertinente à classe em análise.

A apreciação da Figura 5 mostra que as áreas vulneráveis são compostas de significativas porções territoriais de áreas de média suscetibilidade, sempre com proporções superiores a $66 \%$ de participação nas áreas vulneráveis.

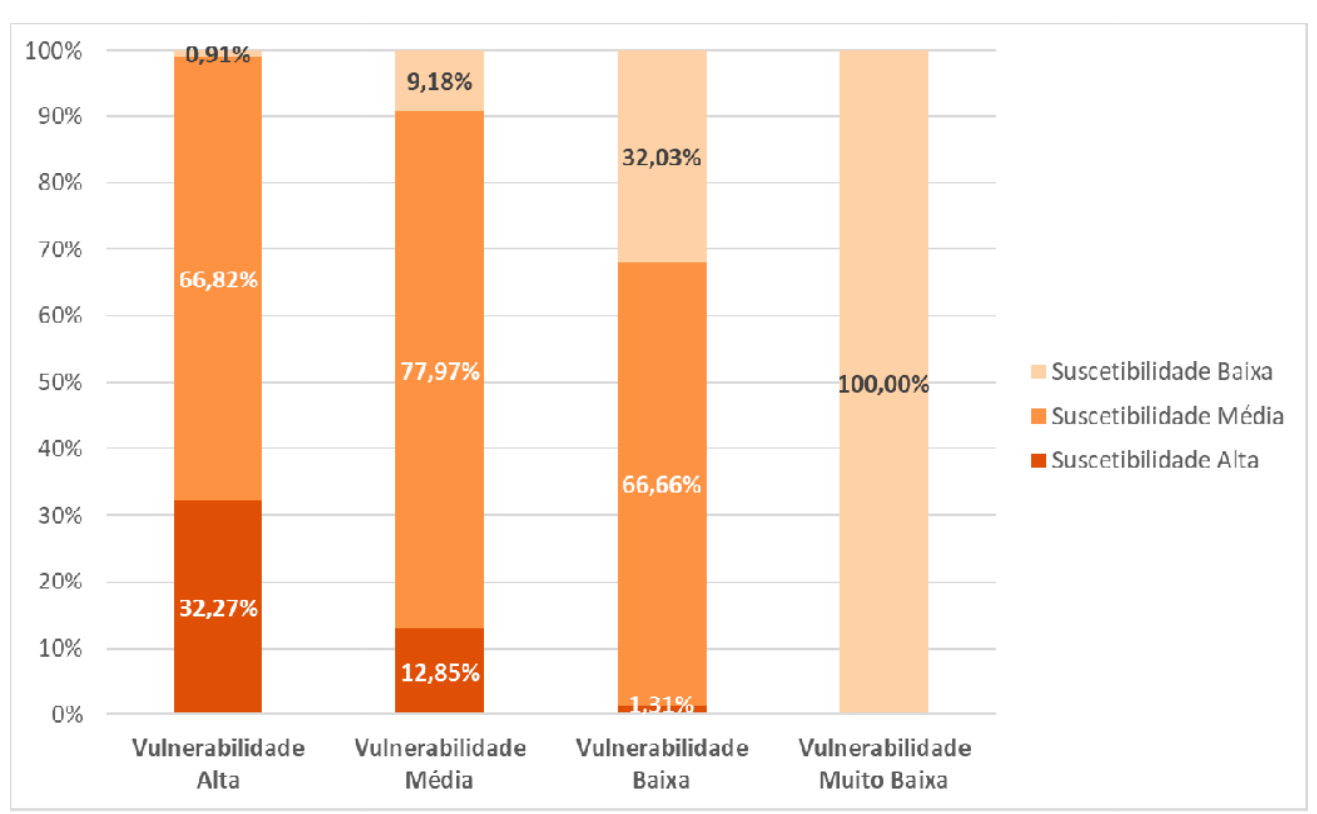

Figura 5. Distribuição percentual das áreas suscetíveis no mapa de áreas vulneráveis. Fonte: Elaborado pelos autores.

De acordo com a Figura 5, a suscetibilidade alta tem pouca participação espacial na definição das áreas relacionadas às classes de vulnerabilidade. Isso se torna exceção para a categoria Alta Vulnerabilidade, pois aproximadamente $1 / 3$ de sua área $(14.352,47 \mathrm{ha})$ é composta por superfícies de alta suscetibilidade. Essa mesma proporção é verificada na classe Vulnerabilidade Baixa, mas o fator baixa suscetibilidade é quem se diferencia ao abranger uma área de 17.170,98 hectares.

A classe Vulnerabilidade Muito Baixa possui $100 \%$ de sua área composta pelo fator suscetibilidade baixa. Isso representa uma área de 4.257,70 hectares.

\section{Conclusões}

A identificação de áreas vulneráveis, de acordo com a abordagem deste trabalho, representa a quarta etapa da modelagem conceitual das áreas de risco de ocorrência de acidentes com transporte rodoviário de produtos perigosos, juntando-se às três fases anteriores, correspondentes às áreas de periculosidade, de suscetibilidade e de criticidade. Sendo estas duas últimas integrantes da vulnerabilidade.

Com base nos resultados e discussão, pode-se afirmar que, a partir da compartimentação da área em questão, os pesos e notas atribuídos aos planos de informação tendem a qualificar a criticidade como o parâmetro que detém a maior responsabilidade na definição dos trechos que se apresentam como aqueles de maior vulnerabilidade, uma vez que os parâmetros de suscetibilidade homogeneizaram a avaliação.

Por fim, os resultados obtidos apresentam um quadro sinótico dos graus de exposição em que os recursos humanos, naturais e patrimoniais estão sujeitos aos acidentes envolvendo o transporte rodoviário de produtos perigosos. Com base nisso, o estudo pode contribuir para a elaboração de projetos ou programas de prevenção ou redução de prejuízos à saúde humana e à saúde ambiental, bem como aos bens estratégicos de produção. 


\section{Referências}

ALHEIROS, M. M. Avaliação econômica de perdas ambientais na análise de riscos geológicos. In: Encontro Nacional da ECOECO, 1., 1996, Campinas. Anais... Rio de Janeiro: Sociedade Brasileira de Economia Ecológica, 1996, p. 1-3.

ALONSO, M. A. et al. (Ed.). Guía para la elaboración de estudios del medio físico: contenido y metodología. 5. ed. Madrid: Mopu, Ceotma, 2004. 804 p. Disponível em: $<$ https://bit.ly/2X2rZR5>. Acesso em: 13 jan. 2019.

ANDRADE, E. L. Áreas de risco ambiental aos acidentes com transporte rodoviário de produtos perigosos no trecho alagoano da rodovia BR-101: Uma proposta metodológica. 2016. 192 p. Dissertação (Mestrado em Geografia) - Universidade Federal de Alagoas, 2016.

BELTRAMI, A. C. Acidentes com produtos perigosos: análise de dados dos sistemas de informações como subsídio às ações de vigilância em saúde ambiental. 2009. 46 f. Dissertação (Mestrado em Saúde do Trabalhador e Ecologia Humana) - Escola Nacional de Saúde Pública, Rio de Janeiro, 2009. Disponível em: $<$ http://bit.ly/2ILC1m0>. Acesso em: 05 jan. 2019.

BRASIL. Decreto-lei n. 2.063, de 6 de outubro de 1983. Dispõe sobre multas a serem aplicadas por infrações à regulamentação para a execução do serviço de transporte rodoviário de cargas ou produtos perigosos e dá outras providências. Diário Oficial [da] República Federativa do Brasil, Brasília, DF, 7 out. 1983.

BRASIL. Decreto no 96.044, de 18 de maio de 1988. Aprova o Regulamento para o transporte rodoviário de produtos perigosos e dá outras providências. Brasília, DF: Diário Oficial [da] República Federativa do Brasil, 19 maio 1988.

BRASIL. Congresso; Câmara dos Deputados. Portaria $\mathbf{n}^{0}$ 291, de 31 de maio de 1988. Baixas instruções complementares ao regulamento do transporte rodoviário de produtos perigosos. Brasília, DF: Diário Oficial [da] República Federativa do Brasil, 16 jun. 1988.

BRASIL. Decreto $\mathbf{n}^{0} \mathbf{8 7 5}$, de 19 de julho de 1993. Promulga o texto da convenção sobre o controle de movimentos transfronteiriços de resíduos perigosos e seu depósito. Brasília, DF: Diário Oficial [da] República Federativa do Brasil, 20 jul. 1993.

BRASIL. Decreto no 1080, de 8 de março de 1994. Regulamenta o fundo especial para calamidades públicas (Funcap) e dá outras providências. Brasília, DF: Diário Oficial [da] República Federativa do Brasil, 9 mar. 1994.

BRASIL. Agência Nacional de Transportes e Tráfego. Resolução nº 420, de 11 de fevereiro de 2004. Aprova As Instruções Complementares Ao Regulamento do Transporte Terrestre de Produtos Perigosos. Brasília, DF: ANTT, 12 fev. 2004.

BRASIL. Departamento Nacional de Infraestrutura de Transportes. Ministério dos Transportes. IPR-711: manual rodoviário de conservação, monitoramento e controle ambientais. 2 ed. Rio de Janeiro. Ministério dos Transportes, 2005. $68 \mathrm{p}$.

BRASIL. Departamento Nacional de Infraestrutura de Transportes. Ministério dos Transportes (Org.).

Anuário estatístico das rodovias federais 2010: Acidentes de trânsito e ações de enfrentamento ao crime. Brasília: Ministério dos Transportes e Ministério da Justiça, 2011. 687 p. Disponível em:

$<$ http://bit.ly/2KC2a8R >. Acesso em: 11 jun. 2019.

BROOKFIELD, H. Environmental damage: distinguishing human from geophysical causes. Environmental hazards: human and policy dimensions, v.1, n.1, p. 3-11, jun. 1999.

CALHEIROS, S.Q.C. Turismo versus agricultura no litoral meridional de Alagoas. 2000. v.1 e 2. Tese (Doutorado em Geografia) - Universidade Federal do Rio de Janeiro, Rio de Janeiro, 2000.

CHAKRABORTY, J.; MAANTAY, J. A.; BRENDER, J. D. Disproportionate proximity to environmental health hazards: Methods, models, and measurement. American Journal of Public Health, v. 101, n. 1, $27-$ 36, 2011. Disponível em: <http://bit.ly/31XAAsf>. Acesso em: 15 mar. 2019.

COELHO, L. R. BR 101: o caminho de ligação do Brasil. Logística Descomplicada, 2010. Disponível em: $<$ http://bit.ly/2xg5TQA >. Acesso em: 5 jun. 2019.

COIMBRA, C. Visão histórica e análise conceitual dos transportes no Brasil. Rio de Janeiro: Cedop, 1974. $364 \mathrm{p}$. 
CONFEDERAÇÃO NACIONAL DO TRANSPORTE (Brasil). Anuário CNT do Transporte 2018. CNT, 2018. Disponível em: <http://bit.ly/2ZM78Dm>. Acesso em: 08 mar. 2019.

COSTA, M. A. da. O transporte de produtos perigosos no Brasil (parte 1/3). Logística Descomplicada, 2013. Disponível em: <http://bit.ly/2RyVaKB>. Acesso em: 9 jun. 2019.

CUTTER, S. L. Vulnerability to environmental hazards. Progress in Human Geography, v. 20, n. 4, 529$539,1996$.

INSTITUTO DE LOGÍSTICA E SUPPLY CHAIN. Panorama ILOS: Custos logísticos no Brasil. Rio de Janeiro: Ilos, 2016.

ENOMOTO, C. F. Método para elaboração de mapas de inundação: estudo de caso na bacia do rio Palmital, Paraná. 2004. 132 f. Dissertação (Mestrado em Engenharia de Recursos Hídricos e Ambiental) Universidade Federal do Paraná, Curitiba, 2004.

FRIESECKE, F. Precautionary and sustainable flood protection in Germany: strategies and instruments of spatial planning. Proceedings of 3rd FIG Regional Conference, Jakarta, 2004. Proceedings... Jakarta, 2004.

HOSSINI, V. The rule of vulnerability in risk management. Bonn: UNU, 2008. 51 p. Disponível em: $<$ http://bit.ly/2J1vhza $>$. Acesso em: 25 jun. 2019.

INSTITUTO DE PESQUISA ECONÔMICA APLICADA; Departamento Nacional de Trânsito; Associação Nacional de Transportes Públicos. Impactos sociais e econômicos dos acidentes de trânsito nas rodovias brasileiras: relatório executivo. Brasília, DF: Ipea, 2006. 80 p. Disponível em: <http://bit.ly/2YedTNZ>. Acesso em: 7 jun. 2019.

PÉCURTO, P. C. F. Criação de um modelo para a implementação de um sistema de informação geográfica, à escala nacional, para a gestão da cartografia municipal de risco. 2010. 53 f. Dissertação (Mestrado Ciências Sociais e Humanas) - Universidade Nova de Lisboa, Lisboa, 2010. Disponível em: $<$ http://bit.ly/2X3s8Ui>. Acesso em: 6 abr. 2019.

REBELO, F. Riscos naturais e acção antrópica: estudos e reflexões. 2. ed. Coimbra: Imprensa da Universidade de Coimbra, 2003. 289 p. Disponível em: <http://bit.ly/2RDDi11>. Acesso em: 1 abr. 2019.

SANTOS, J. de O. Relações entre fragilidade ambiental e vulnerabilidade social na susceptibilidade aos riscos. Mercator, v. 14, n. 2, 75-90, 2015. DOI: http://dx.doi.org/10.4215/rm2015.1402.0005. Disponível em: <http://bit.ly/2ZLR2d2>. Acesso em: 29 dez. 2018.

SERMAN, C. Análise dos aspectos críticos em processos de concessão de rodovias. 2008 . $287 \mathrm{f}$. Tese (Doutorado em Ciências em Engenharia de Transporte) - Universidade Federal do Rio de Janeiro, Rio de Janeiro, 2008.

STRAUCH, C. E. Acidentes com produtos químicos perigosos no transporte rodoviário no estado do Rio de Janeiro: propostas de melhoria nas ações que visam respostas emergenciais. 2004. 238 f. Dissertação (Mestrado em Engenharia) - Universidade do Estado do Rio de Janeiro, Rio de Janeiro, 2004. Disponível em: $<$ http://bit.ly/2YljmCV>. Acesso em: 5 nov. 2018.

UNITED NATIONS (UN). Recommendations on the transport of dangerous goods: Model Regulations. 20. ed. New York And Geneva: UN, 2017. 880 p. Disponível em: <http://bit.ly/2WZuZOl>. Acesso em: 25 jun. 2019.

XAVIER DA SILVA, J. Geoprocessamento para análise ambiental. Rio de Janeiro: J. Xavier da Silva, 2001. 228p. 